\title{
ASO Author Reflections: Identifying Rectal Cancer Patients Suitable for Watch-and-Wait
}

\author{
Jin K. Kim, MD, and Julio Garcia-Aguilar, MD, PhD \\ Benno C. Schmidt Chair in Surgical Oncology, Colorectal Service, Department of Surgery, Memorial Sloan Kettering \\ Cancer Center, New York, NY
}

\section{PAST}

Implementing the watch-and-wait (WW) approach for rectal cancer patients who respond well to neoadjuvant therapy is oncologically safe and can preserve the patient's quality of life that often is sacrificed by total mesorectal excision (TME). ${ }^{1,2}$ However, the data of WW on patient survival are limited to retrospective studies ${ }^{3}$ because a prospective randomized trial comparing TME with WW is not feasible.

\section{PRESENT}

A retrospective study at a comprehensive cancer center analyzed the rates for WW use among five expert colorectal surgeons and investigated the association of WW with organ preservation rates and disease-free survival. ${ }^{4}$ The management by WW versus immediate TME for patients treated with neoadjuvant therapy varied significantly among the surgeons $(p<0.0001)$. The long-term organ preservation rates also varied from 7 to $39 \%$ among the treating surgeons, with higher rates noted for surgeons who offered WW more frequently. Disease-free survival was similar $(p=0.2)$.

\section{FUTURE}

The study findings suggest that wide adoption of WW is associated with increased organ preservation without compromising oncologic outcomes. Rectal cancer patients who

(C) Society of Surgical Oncology 2021

First Received: 20 September 2021

Accepted: 21 September 2021;

Published Online: 6 October 2021

J. Garcia-Aguilar, MD, $\mathrm{PhD}$

e-mail: garciaaj@mskcc.org respond well to neoadjuvant therapy can be offered WW to achieve organ preservation, which has positive implications for quality of life. ${ }^{2}$ Additional research to maximize response rates and improve diagnostic tools to better identify responders may provide more confidence for the surgeon to offer WW.

\section{DECLARATIONS}

CONFLICT OF INTEREST Julio Garcia-Aguilar: Ethicon J\&J Consultant; daVinci Intuitive - Consultant/Stock.

\section{REFERENCES}

1. van der Valk MJM, Hilling DE, Bastiaannet E, et al. Long-term outcomes of clinical complete responders after neoadjuvant treatment for rectal cancer in the International Watch \& Wait Database (IWWD): an international multicentre registry study. Lancet. 2018;391:2537-45. https://doi.org/10.1016/S0140-6736(1 8)31078-X.

2. Quezada-Diaz FF, Smith JJ, Jimenez-Rodriguez RM, et al. Patientreported bowel function in patients with rectal cancer managed by a watch-and-wait strategy after neoadjuvant therapy: a casecontrol study. Dis Colon Rectum. 2020;63:897-902. https://doi. org/10.1097/DCR.0000000000001646.

3. Dossa F, Chesney TR, Acuna SA, Baxter NN. A watch-and-wait approach for locally advanced rectal cancer after a clinical complete response following neoadjuvant chemoradiation: a systematic review and meta-analysis. Lancet Gastroenterol Hepatol. 2017;2:501-13. https://doi.org/10.1016/S2468-1253(17)30074-2.

4. Kim JK, Thompson H, Jimenez-Rodriguez RM, et al. Adoption of organ preservation and surgeon variability for patients with rectal cancer does not correlate with worse survival. Ann Surg Oncol. 2021. https://doi.org/10.1245/s10434-021-10877-3.

Publisher's Note Springer Nature remains neutral with regard to jurisdictional claims in published maps and institutional affiliations. 